\title{
Pain management - the global sound of silence
}

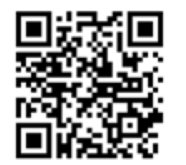

Worldwide, and particularly in South Africa (SA), patients are unwittingly forced to suffer in silence because doctor training in formal pain management is almost nonexistent, with the best local medical campus undergraduate pain training consisting of 'about four hours' in a student's fourth or fifth year.

This is according to Cape Town-based anaesthetist Dr Milton Raff, a member of the International Association for the Study of Pain (IASP) and the Developing Countries Working Group and former president of Pain SA, who said that the best country for pain management training is France. 'It's absolutely shocking, he said on describing the findings of an IASP study of pain education in developing countries (published in the British Journal of Pain in 2012 $\left.2^{[1]}\right)$. South America, Africa and the Indian sub-continent proved to have 'very, very poor pain education at undergraduate level'. Then in 2012 the IASP shifted the survey spotlight to First-World countries, canvassing 242 medical schools in Europe. (This was the APPEAL (Advancing the Provision of Pain Education and Learning) Study, the first-ever Europe-wide review of pain education for undergraduates in Europe. Conducted by independent research company Adelphi Research in 15 European countries and involving review of publicly available curricula from 242 undergraduate medical schools, it went beyond existing research by providing a more comprehensive analysis and understanding of pain learning. The research was conducted from April to September 2013, is part of a Europe-wide initiative aimed at raising the profile and importance of pain education, and was funded by Mundipharma International Ltd.) They found that pain management training consisted on average of about $0.2 \%$ of a medical student's curriculum over their full 6 years of training. A total of 17 European medical schools had no pain education of any kind, while the rest claimed to have integrated the subject into other training blocks - but were unable to quantify this.

\section{North America - animals in pain better} off than humans

'We thought that North America [Canada and the USA] would perhaps be better, but guess what? They were as bad. We actually found that vets in North America get 20 times more attention paid to pain management in their training, meaning that animals get better treated there than human beings.' On home turf, a survey of SA's nine medical schools revealed that only the University of the Free State had a dedicated full-time pain unit, backed by a 'few hours-long' standalone pain management course, something unique to that campus. 'The others claimed it was integrated into their other subjects, but the best I could find was via a family

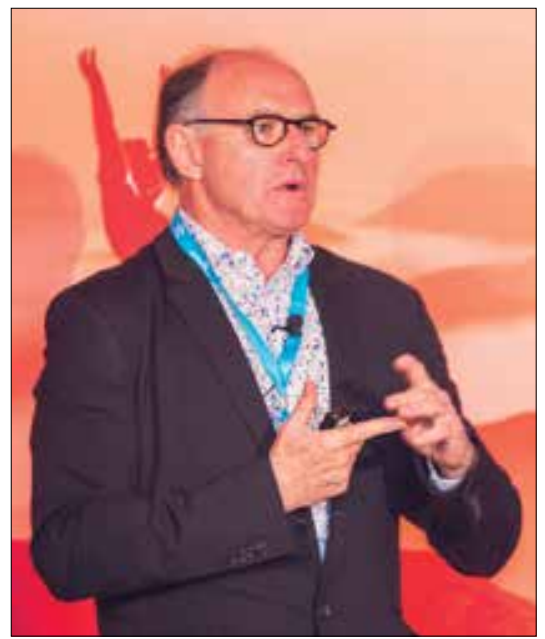

Dr Milton Raff.

medicine block where undergraduates got three to four hours in their fourth year,' says Raff. 'Overall students are absolutely under-equipped to manage both acute and chronic pain when they leave university in SA. Globally and locally, there are no clinical end-points prescribed that enable a newly graduated medical practitioner to deal with pain issues.' A check on postgraduate training in SA also provided little cause for celebration. It ranged from Bloemfontein's full-time pain clinic to part-time pain clinics at Stellenbosch University, the University of Cape Town and the University of the Witwatersrand. However, Prof. Richard Hift, chair of the Committee of Medical 


\section{Medical training: 'We are more than our diseased organs' - Dean}

In most medical curricula, undergraduate and postgraduate, there is a serious lack of exposure to non-discipline-bound, syndrome-centred experience and instruction such as in pain, depression and disability, admits Prof. Richard Hift, Chair of the Medical Committee of Deans and Dean of the School of Clinical Medicine at the University of KwaZulu-Natal.

This was the consequence of a hundred years of narrowly specialty-based training programmes that by their very nature have tended to focus on organ systems rather than the organism as a whole - in all senses, physical, psychological and social, he adds. 'Sadly, deans are not being petulant in stating that new topics can only enter into the curriculum if something else drops out - it is no secret that curricula are subject to serious, increasing overload. He says the solution did not lie in devoting 'some extra hours' to orphan subjects such as pain management. An intermediate step was the reprioritisation of topics within the curricula. However, the only genuine and lasting solution lay in fundamentally redesigning undergraduate curricula so that they were centred around the problems experienced by people, and not the diseases that affect their organs.

This was not a new sentiment. 'Thinking colleagues have been urging this for decades - but medical schools worldwide have proved themselves extraordinarily resistant to attempts to bring about radical curricular reform in the clinical years, and to shift the focus away from department-led teaching to something much less rigid and more generalist and holistic in nature.' A number of initiatives were being explored around the world, and at UKZN 'we've just commenced planning our "CCCP" [continuous clinical and community placement programme] curriculum, which will see students working for long, uninterrupted periods in non-specialist hospital, clinic and community settings. Although our specialist departments will have an important contribution, it will be as enhancers of learning in this setting, not as the dominant providers. We hope to move away from organs and their diseases to people and their problems - and this very much includes enhanced competence in dealing with the physically failing body. It is a move away from narrow, technical excellence to another form of excellence - global proficiency in promoting, maintaining and restoring health.' Among many advantages of such a system would be the space to ensure that important issues such as pain management were comprehensively and holistically addressed over periods of months of clinical experience, rather than in the form of 'a bolus of information injected into an already crowded curriculum'. One of the most 'crippling fallacies' in medical education was that brief exposure to a topic (and by brief, Hift means even exposure as long as the typical clinical block of 4 - 6 weeks) was sufficient to result in lasting changes in understanding, performance and behaviour. 'Sadly, there are many parallels among our traditional system for the training of postgraduates, our specialists.'

In the meantime, Dr Raff and his colleagues around the country were to be congratulated on their important initiative. 'There is little in human experience that is as debilitating as chronic severe pain, and it is indeed an area that deserves a much stronger focus than it has traditionally received,' says Hift.

Deans, said that there were now also active, enthusiastic interdisciplinary and researchproductive pain clinics at Grey's Hospital in Pietermaritzburg and Inkosi Albert Luthuli Central Hospital in Durban.

Raff said that unless you were 'rotating through the pain clinic discipline in your postgraduate training [as an anaesthetist], it's unlikely that as a specialist in any other discipline you'd have ever worked in a pain clinic. This meant that doctors were not clinically equipped to diagnose and treat pain states, leading ultimately to poor management and patient dissatisfaction.

Far from just complaining, Raff and his associates at Pain SA (which acts as the local chapter of the IASP) have grasped the nettle, working through the examining body, the SA Colleges of Medicine, to create a postgraduate subspecialty in pain management that will be submitted to the Health Professions Council of South Africa for registration. Asked when this might become available, he said that the aim was to begin training in 2017, but cautioned that with the current pressure on expanded medical training platforms, very few hospitals would be able to do it. Izindaba has established that probably only Helen Joseph Hospital in Gauteng and Pelonomi Hospital in Bloemfontein will be likely to offer this training. When this was put to Raff, he reluctantly confirmed it.

With pain under-treated, under-managed and poorly managed across the globe, the IASP chapters took on medical deans in their own countries, but the overarching response was that training would have to be at the expense of some other discipline - summed up, Raff said, in the 'petulant response' of 'OK, you want pain, we take out appendicitis.' 'So it's recognised, but very little is done about it', he added.

Pain SA has garnered some overseas funding to train three African fellows per annum in pain management (two Nigerians and one Mauritian at present), resulting in IASP certification after an intensive 3-month course. Raff began the training in Cape Town with assistance from Dr Rene Krause at St Luke's Hospice. The current incumbents are being trained at academic hospitals attached to the universities of KwaZulu-Natal and the Free State. Raff has kicked off two other ongoing pain management courses, the first in his current capacity as chair of the Pain Committee of the World Federation of Anesthetists (WFA). Called Essential Pain Management and sponsored by the WFA, the weekend course, split between Cape Town, Johannesburg and Pretoria, usually sees between 20 and 30 doctors enrolling. 'It's very basic, but more than they've ever got,' says Raff. Focusing on pain as a disease and its diagnosis and management, the course moves doctors away from the traditional view of pain as merely symptomatic. The second course, cleverly entitled 'Know Pain' and with the intention of creating a ripple effect via a 'train the trainer' programme, is more intensive. Sponsored by Pfizer through a non-restrictive educational grant, the course is delivered pro bono by Pain SA members. The first 20 doctors enrolled in mid-June for the nine modules on various aspects of pain.

\section{Holistic approach to pain sadly lacking}

Raff said that the various private initiatives should begin to have some impact, albeit far short of what was required. He says that the average private GP cannot afford to see a patient for more than 14 minutes, which is less than half the time required by a patient in pain. 'You have to use a biopsychosocial approach, because the disease itself has so many implications, not the least of which is depression.' Equity in access to pain management remained a huge headache because only the luckier patients would get 
referred to a pain clinic that adopted the correct holistic, multidisciplinary approach. This meant that $80 \%$ of the population would probably remain without any pain management, 'unless you're really lucky and end up in the Bloemfontein clinic - which probably reduces the overall burden by about one per cent'. Raff stressed that many state pain patients were Workmen's Compensation Act cases, which meant that pain management was automatically excluded from any funding benefits. 'So we're sitting with a government and parastatals that don't recognise that pain is a disease entity on its own. So you have people dropping out of work and costing the economy billions every year, not to mention the cost in the quality of family life, he said.

Partly because of lack of training, doctors were reluctant to use highly effective opioids such as morphine, particularly with children, whose pain management differed both emotionally and physically from that of adults. 'Apart from Red Cross Children's
Hospital [Cape Town], the way kids' pain is handled countrywide is shocking, he added.

Dr Liz Gwyther, chair of the International Hospice and Palliative Care Association and CEO of its local equivalent, said there was no doubt that training in pain assessment and management must be improved and that Pain SA was doing a good job in providing it. 'It is always difficult to add courses to busy undergraduate curricula. Pain assessment and management is also taught in palliative care, which needs to be strengthened in undergraduate curricula - we find it more effective to provide training to academic lecturers and encourage them to integrate this into their courses. In this way palliative care and pain management become part of current courses without having to find dedicated time in the curriculum. We're encouraged by the new Comprehensive Pain Management division being set up at UCT by Dr Romy Parker, she added.
Prof. Errol Holland, a former chair of the Committee of Medical Deans, said that current curricula were so full that pain management had become an 'orphan' discipline. 'I totally agree that it's something so fundamental that it needs to be addressed properly', he added. His successor, Prof. Hift, said that Dr Raff and his colleagues around the country were to be congratulated on their important initiatives. 'There is little in human experience that is as debilitating as chronic severe pain, and it is indeed an area that deserves a much stronger focus than it has traditionally received, he added (see side-bar story, p. 622).

\section{Chris Bateman}

chrisb@hmpg.co.za

S Afr Med J 2015;105(8):621-623.

DOI:10.7196/SAMInew.8083

1. Bond M. A decade of improvement in pain education and clinica practice in developing countries: IASP initiatives. $\mathrm{Br} \mathrm{J}$ Pain 2012, 6(2):81-84. [http://dx.doi.org/10.1177/2049463712444062] 